\title{
EL PENSAMIENTO ECONOMICO ILUSTRADO Y LAS COMPANIAS DE COMERCIO
}

MARIANO GARCIA RUIPEREZ

Uno de los aspectos menos conocidos de la economía dieciochesca sigue siendo, aún hoy día, el de las compañías por acciones, que durante ese período tuvieron un auge espectacular. De poco han servido las palabras de Carmelo Viñas Mey, que ya en 1922 subrayó la importancia que tendría el conocimiento de la trayectoria de estas instituciones, porque a la historia de las creadas en España iba unida la incesante actuación, durante los siglos xvir y xviII, por recuperar nuestra hegemonía económica, y porque en ellas se creyó hallar el instrumento seguro para lograr ese objetivo, sin olvidar su papel nada despreciable en nuestro resurgimiento industrial, sobre todo en el sector textil ${ }^{1}$.

Tanto Manuel Colmeiro ${ }^{2}$ como el propio Viñas Mey atribuyeron la aparición de las grandes compañías comerciales europeas, de forma indirẻcta, a nuestro país, por el cierre del comercio con Holanda a principios del siglo Xvir.

A pesar de estos antecedentes, son muy escasos los estudios llevados a cabo sobre el tema. Las Memorias políticas y económicas... de E. Larruga y Boneta sigue siendo la obra impresa fundamental; en ella y en los escasos fondos que se conservan en los Archivos de Simancas e Indias se han basado todos los estudios posteriores, desde el del propio M. Colmeiro, pasando por la obra clásica de J. Carrera Pujal, los artículos de J. Martínez Gijón, G. J. Jiménez Sánchez y F. J. Lasarte Alvarez, M. J. Matilla Quizá y J. Clayburn la Force, como análisis generales ${ }^{3}$. No hay que olvidar los dedicados a cada compañía en particular, sobre todo a aquellas que nacieron con un claro carácter privilegiado bajo la supervisión de la Junta de Comercio y Moneda. Sobre la Guipuzcoana o la de Filipinas la bibliografía es abundante ${ }^{4}$, pero en peor situación se encuentran las denominadas compañías industriales interiores, y salvo la de Extremadura, analizada por M." Carmen Rodríguez Gonzá-

Viñas Mey (1922), pp. 240-241.

2 Colmeiro (1965), vol. II, pp. 1041-1043.

3 Véase bibliografía.

Sobre la de Caracas, baste citar los estudiós de Ramón Basterra, N. Soraluce Zubizarreta, J. Estornes Lasa... 
lez ${ }^{5}$, sólo tienen estudios parciales la de Granada, la de Zaragoza y la de Burgos ${ }^{6}$. Un modelo a seguir es la obra clásica de M. Capella Martínez y A. Matilla Tascón sobre Los Cinco Gremios Mayores de Madrid ${ }^{7}$.

Si, como ha subrayado J. Muñoz Pérez, los temas que dominan la política económica en el siglo xvirI son la reorganización de la Hacienda, el fomento de los recursos económicos y la rehabilitación del comercio español, especialmente del de Indias ${ }^{8}$, no nos ha de extrañar el importantísimo papel que desempeñarán las compañías de comercio para intentar conseguir estos objetivos.

En el siglo xvirI, actividades bien distintas serán realizadas a través de compañías por acciones. Con la intención de hacer resurgir nuestro decaído comercio con zonas marginadas del tráfico gaditano-americano fueron creadas las Compañías de Honduras, Galicia, Guipuzcoana de Caracas, la Habana, Barcelona y Filipinas. Las de Zaragoza, Granada, Sevilla, Toledo, Extremadura, Ezcaray, Requena, Segovia, Burgos, Nuestra Señora de los Desamparados de Valencia... tuvieron como fin la revitalización de nuestra industria textil y la mejora de su comercialización. Con fines puramente comerciales nació la Compañía de los Cinco Gremios Mayores de Madrid. Otras tuvieron una actividad muy concreta, como la Compañía del Coral, estudiada por Palacio Atard; la Compañía de Impresores y Libreros de Madrid, la Real Compañía de Droguería, la de Fábricas y Comercio de Pozuelo (curtido de pieles), la Compañía Marítima de Pesca... También por acciones se tigieron las sociedades bancarias (Banco de San Carlos), y mucho mayor fue su desarrollo en el ramo de los seguros 9 .

Las compañías entre particulares, comandatarias, fueron aún más numerosas, y no por eso están mejor estudiadas ${ }^{10}$.

Sin embargo, las que más llamaron la atención entre sus contemporáneos fueron las creadas bajo iniciativa estatal, y con un claro carácter privilegiado con respecto a la mayoría de fabricantes y comerciantes particulares, al gozar de la protección de la Corona. Dentro de planteamientos puramente mercantilistas, se pretendió con su creación facilitar la instalación de fábricas, sobre todo en el sector textil, y mejorar la comercialización de nuestras produccio-

${ }^{3}$ Su análisis deja muchas lagunas, resultanao más completo el estudio de $\mathrm{M}$. J. Matilla Quizá, que dedica las pp. 384-389 a esta Compañía.

- Palacio Atard (1960), pp. 117-139.

? Los autores analizan también las vicisitudes de las compañías particulares formadas por cada gremio.

- Muñoz Pérez (1955), p. 190.

9 El estudio mejor de conjunto es, sin duda, el de Matilla Quizá.

${ }^{10}$ Salvo Pierre Vilar, que lo hizo en Cataluña, o A. García Baquero, que lo ha hecho en Cádiz, faltan estudios particulares como el de Navarro Miralles (1980) y, por supuesto, obras de conjunto. 
nes, en un intento de nivelar nuestra desfavorable balanza comercial y evitar la salida de numerario.

Si en el siglo xvir no dejaron de ser meros proyectos ", durante el Siglo de las Luces serán una realidad, de la mano, sobre todo, de ministros de la talla de Patiño, Carvajal y Lancaster y el conde de Floridablanca. De ahí que buena parte de nuestros ilustrados reflejen en sus obras su parecer acerca de estas instituciones novedosas. Defensores y críticos se apoyaron en la realidad para refrendar sus juicios, constituyendo uno de los temas más polémicos, sobre todo en los años centrales del siglo. Pero el interés por las compañías de acciones venía de atrás.

En 1680, Antonio Somoza y Quiroga, en su Unico desengaño y perfecto remedio de los menoscabos de la Corona de Castilla, expresaba la necesidad de crear para el comercio de Indias la «Compañía de Españoles, Frutos, Fábricas y Maniobras destos Reynos» ${ }^{12}$, siguiendo las ideas de fray Juan de Castro.

De la misma opinión era Manuel de Lira, que en su Representación dirigida a Carlos $I I^{13}$ creía en la conveniencia de erigir una Compañía General de Comercio, con sede en Cádiz o en Sevilla, que gozase de considerables privilegios, y con la que preveía la desaparición del comercio clandestino en Indias por parte de ingleses y holandeses, al participar éstos, en calidad de accionistas, en la Compañía española.

Aunque, sin duda alguna, la figura más representativa, de finales del siglo XviI, por su apoyo a estas sociedades comerciales es Miguel Alvarez Osorio y Redin. Si en su Zelador para el bien común de $\operatorname{todos}^{14}$ ya señalaba como único remedio para evitar la destrucción de España que los mercaderes formasen una compañía general de comercio y fábricas, más explícito y rotundo se mostró en otro de sus Discursos, poco conocido, y que lleva por título Compañia Universal de Fábricas y Comercios, y breve resumen de los medios más ciertos, y practicables, para único remedio de esta Corona ${ }^{15}$. A cargo de ésta estarían todas las fábricas del reino, y entre los medios para formar tan importante empresa subraya que:

Todos los vecinos de estos Reynos, de qualquier estado o caliJad, han de ayudar a la Compañía de Fábricas y Comercio, unos con sus caudales y otros con sus personas, sin que a persona alguna le obste para los actos positivos de nobleza. Todos los que

"Sobre éstos véase, por ejemplo, Hussey (1934), cap. I.

${ }_{12}$ Somoza y Quiroga (1680), p. 25.

${ }_{13}$ Memoires et considerations (1761), tomo I, pp. 43-44.

${ }^{14}$ Rodríguez de Campomanes (1775-77), tomo I, p. 271.

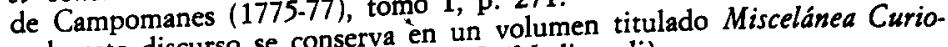
sa, tomo II, fols. 183-190, en la Biblioteca del CSIC (Medinaceli). 
quisieren han de poner sus caudales, y todos los que pudieren han de ayudar con la dézima parte de sus rentas todos los años...

En ella debían formar parte todos los eclesiásticos con sus bienes, los de las Ordenes militares y los de los interesados particulares. El Rey la debia conceder, por treinta años, todos los beneficios que produjeran las vacantes en la provisión de arzobispados, obispados, capellanías... La compañía prestaría a los fabricantes el dinero para realizar sus manufacturas y a cambio recibiría sus géneros, una vez confeccionados. $\mathrm{El}$ dinero y bienes recogidos por la compañía en una diócesis determinada sería invertido en ella. Se encargaría de dirigir todas nuestras fábricas y comercio, tanto interior como exterior, situando almacenes generales en las principales ciudades... Para Osorio y Redin, todos nuestros males se solucionarían si se llevaba a la práctica su ambicioso proyecto, aunque nada nos diga sobre su organización y dirección, pecando en exceso su discurso de idealismo, como ocurrió con soluciones parecidas dadas en ese siglo por otros arbitristas.

Gaspar Naranjo y Romero representa una postura unificadora. En su obra Antorcha que alumbra para empezar la restauración económica de España por medio de su comercio interior y fábricas de sus naturales ${ }^{16}$ recogerá posturas expuestas anteriormente, pues para fomentar el comercio interior propuso formar compañías particulares con caudales importantes y, para el exterior, la creación de una compañía universal en Sevilla que gozase del privilegio exclusivo de compra y venta con las demás naciones, a la que incluso concedía el derecho a poseer tropas para evitar posibles fraudes.

Entre las interiores, la más importante sería la que se dedicase al comercio de la lana con carácter monopolista. Tendría su sede en Burgos, y sucursales en todas las cabezas de partido de Castilla. Sus fondos se formarían, aparte de con el caudal de los particulares interesados, con la décima parte de las rentas de los eclesiásticos, con idéntica proporción de las rentas de vínculos y mayorazgos, con la tercera parte de la lana de los ganaderos...

A principios del siglo xvirI estaban claramente expuestas dos formas diferentes, pero no opuestas, de concebir las compañías de comercio en España. Por un lado, se confiaba en ellas para facilitar y aumentar nuestra producción interna y mejorar la comercialización (el nombre de compañías de comercio y fábricas es significativo) y, por otro, se creía necesario modificar el sistema tradicional del comercio indiano con la creación de una compañía que ejercitase éste con carácter monopolístico.

Ejemplo significativo de esta última postura lo representa Juan Legarra, que en 1719, cuando desempeñaba el cargo de secretario del Consejo de $\mathrm{Ha}$ cienda en Sala de Millones, escribió una obra titulada Comercios de España

\footnotetext{
${ }^{16}$ Carrera Pujal (1943-47), tomo III, pp. 84 y ss.
} 
e Indias. Estado actual de ellos; causas de que dimana su decadencia y medios para restablecerlos ${ }^{17}$, en la que se mostrará partidario de la creación de un banco para ayudar a los comerciantes, de una compañía de comercio con Indias y de un tribunal de comercio para restablecer el tráfico hispanoamericano a su antiguo esplendor.

La Compañía General de Españoles, que proponía, debía tener su sede central en Cádiz y sucursales en el resto de las provincias, que habrían de proporcionar los productos exportables a Indias. No obstante, si fracasaba su idea, sugería crear compañías particulares como más factibles en cada una de las provincias.

Contra la corriente imperante a principios del siglo xviri, de apoyo a las compañías de comercio, mostrará su discordancia Jerónimo de Uztáriz. En su clásica Theórica $y$ práctica de comercio $y$ de marina ${ }^{18}$, publicada por primera vez en 1724, subrayará los inconvenientes que produciría el establecimiento de estas instituciones en España. Con su creación, es de la opinión, lo único que se conseguiría sería estancar el comercio en un reducido número de individuos, $y$, además, fracasarían porque en nuestro país no se les podrían dar los privilegios y franquicias que disfrutaban otras como la de Holanda, confundidas casi con la misma soberanía, aparte de que nuestra nación

... no podría conciliarse y entenderse con la flema y espera que necessitan la plantificación, y permanencia de este género de disposiciones, y assumptos, ni con la paciencia que pide lo tardo de sus frutos, mayormente nò produciendo utilidad alguna en los primeros años... ${ }^{19}$.

Uztáriz apoyará sus juicios en los fracasos de las Compañías de Víveres y de Honduras, por lo que siendo difícil, tardío y de dudoso éxito el recurso a este género de compañías no lo consideraba adecuado, ni eficaz, para resolver los problemas económicos del país. El problema no estaba en cómo comerciar, si por compañías, flotas o libremente, sino con qué comerciar. En todo caso, abre la posibilidad de crear compañías de comercio siempre que desarrollasen su actividad con zonas en las que no se tuviese dominio efectivo, o con las que resultase imposible mantener un comercio seguro por medio de embarcaciones armadas que protegiesen a los navios mercantes. Filipinas estaba en el centro de sus pensamientos al emitir estos juicios, pues cree que en España la única compañía que se podría permitir sería

\footnotetext{
1 Legarra (1719), fol. 22.

1 Será la obra de mayor influencia entre los interesados por temas económicos, con varias reediciones en ese siglo $(1742,1757 \ldots)$.

${ }^{19}$ Uztáriz, ed. de 1757 , p. 89.
} 
... la de algunos Negociantes, que se inclinassen a establecer la Navegación, y algún moderado tráfico en las Indias Orientales, navegando por las costas de Africa... ${ }^{20}$.

Por su parte, el autor de los Discursos anónimos sobre el abatimiento en que se hallaba el Comercio de España con sus Indias en el año de $1725 \ldots{ }^{21}$, frente a las ideas de Uztáriz, volvía a resaltar la necesidad de la formación de una compañía que se encargase de todo lo relacionado con el comercio de España con América, a la que el Rey debía proteger y favorecer, ya que pronto conseguiría aumentar la población y fábricas del reino y acabar con el contrabando.

El marqués de Santa Cruz de Marcenado, en su Rapsodia económica política monárquica. Comercio suelto y en Compañias general y particular, publicada un año después de su muerte, acaecida en el sitio de Orán en 1731, insistía en lo gravoso de las cargas tributarias, en lo benéfico del sistema comercial monopolístico y en la formación de compañías de negociantes ingenio-

- sos y ricos, con carácter privilegiado, para favorecer nuestra actividad industrial. Retomando las ideas poco originales de Gaspar Naranjo y Romero, se muestra partidario de crear compañías que dispongan del comercio privativo de un determinado producto durante un período de tiempo concreto:

La Compañía de Fábrica de un género, debe por ciertos años tener el comercio privativo del mismo, y aver para cada género una Compañía diversa, tassando el Rey el preciso número de Associados de cada Compañía...

Acabado el Assiento en las primeras Compañías, puede universalizarse el Comercio de sus respectivos géneros, que antes era privativo, y permitirse de cada uno de ellos más Fábricas a medida del consumo interno y externo ${ }^{22}$.

También defenderá la Compañía General de Indias, recogiendo en su obra, en extracto, un proyecto en este sentido del marqués de Villadarias. En los 32 artículos de los que constaba se analizaba el sistema organizativo, actividades, privilegios..., que debía disfrutar. El monarca, la nobleza, fabricantes y mercaderes unirían sus esfuerzos para formar un capital de 14 millones de pesos. Un consejo en España, otro en México y tres pequeños consejos subdelegados en Perú, Chile y Filipinas se encargarían de la administración de sus recursos. Villadarias solicitaba que dicha compañía debía tener auto-

\footnotetext{
${ }^{20}$ Idem (1957), p. 95.

${ }^{21}$ Original en AHN, Sec. Estado, leg. 3188, exp. 410.

22 Santa Cruz de Marcenado (1732), p. 83.
} 
rización para acuñar moneda, mantener tropas, estar exenta del pago de impuestos...; e incluso el marqués de Santa Cruz irá más lejos que su amigo al prever, como ya había hecho Manuel de Lira, que en la mitad de sus fondos podrían interesarse mercaderes y fabricantes extranjeros, aunque la dirección siempre debía recaer en súbditos españoles.

Difícilmente las colonias mercantiles de Sevilla y Cádiz podrían haber aceptado y apoyado una compañía tan lesiva a sus intereses como la que refleja el proyecto de Villadarias, o los expuestos con anterioridad. Todos los intentos que pretendían acabar con el sistema tradicional impuesto por la Casa de Contratación terminarían en un completo fracaso. Las compañías que se crearon para participar en el tráfico indiano nacieron y se desarrollaron junto a esa organización, no en su contra, dirigiendo sus objetivos a zonas no monopolizadas y marginadas por ese sistema ${ }^{23}$.

Miguel de Zavala y Auñón, en su Representación al Rey Nuestro Señor Don Pbelipe V... dirigida al más seguro aumento del Real Erario, publicada en 1732 , tras defender la única contribución, señalará que, para restablecer nuestro comercio, era necesario formar compañías denominadas por el nombre de las provincias donde se estableciesen o del producto con el que comerciasen. Su idea la resume de la siguiente manera:

Las Compañías que propongo, son un cuerpo de muchos individuos, que contribuyen con sus caudales, con su consejo y con su inteligencia al logro de unas crecidas ganancias; se goviernan con methodo y reglas fixas, y seguras para el acierto; y caminan, baxo la real protección, con establecimientos y con honores ${ }^{24}$.

Para Zavala y Auñón, el comercio por compañías era el más seguro, sus ganancias más crecidas y sus progresos más ventajosos. Aunque en España tendrían que hacer frente a serias dificultades por la poca inclinación de sus naturales a este tipo de negocios, por la oposición que sufrirían de las colonias mercantiles de extranjeros con intereses en nuestro país, por sus inferiores ganancias al tener menos privilegios, por la falta de fe en ellas y por la consideración del ejercicio del comercio como contrario a la nobleza. Aun así, confíaba que con su instauración se establecerían numerosas fábricas, se triplicarían las rentas reales, se evitaría el contrabando...

$Y$ ante la existencia de una compañía que monopolizaba ya el comercio con una zona determinada de Indias, la de Caracas, por lo que ya no se podía crear la famosa Compañía General, es de la opinión de la formación de dos compañías que regulasen el comercio con las zonas más ricas de nuestra Amé-

${ }^{23}$ Matilla Quizá (1982), p. 304.

${ }^{24}$ Zavala y Auñón (1732), p. 203. 
rica: Nueva España y Tierra Firme. La situación monopolística estaría representada no por una, sino por tres compañías.

Por su parte, Bernardo de Ulloa, en su Restablecimiento de las fábricas $y$ comercio español..., aunque refleje claramente la influencia de Jerónimo de Uztáriz, no va a mantener una postura tan rígida como su maestro en cuanto a las compañías de comercio, pues cree que

... se podrán formar Compañías en España, que reciban los simples a precios competentes, dexandole una proporcionada ganancia al Traficante de mar, y dichas Compañías los mantendrán, y darán a los fabricantes con un cinco por ciento de utilidad... ${ }^{25}$.

Sin embargo, al hablar del tráfico indiano su postura es inmovilista: ni navíos sueltos ni compañías. De estas últimas dice que, aparte de ser una especie de estanco perjudicial al comercio general de España, no evitarían el contrabando. Ulloa sostiene como menos malo el sistema de flotas y galeones de manos de la Casa de Contratación.

También en 1740, Dionisio Alsedo y Herrera ponía en conocimiento del público lector sus Noticias del Perú, Tierra Firme, Cbile y Nuevo Reyno de Granada ${ }^{26}$, en las que proponía como remedio eficaz para los males de esta zona que en todos los puertos de Tierra Firme hubiera otra Compañía Guipuzcoana.

La obra de José Campillo y Cossío apenas presta atención al tema, pues la única referencia que se encuentra en Lo que hay de más y de menos en España... hace mención a la necesidad de que gremios o compañías de crecidos fondos tomasen bajo ciertas condiciones las fábricas que hasta entonces administraba el Real Erario ${ }^{27}$. Tampoco Melchor de Macanaz mostró un mayor interés, ya que ni en los Auxilios para bien gobernar... ni en su Representación que bice y remití... ${ }^{23}$ reflejó su toma de postura, aunque hay que tener en cuenta que la paternidad de estas obras ofrece muchas dudas ${ }^{29}$.

Más prolijo en sus juicios resultó ser Teodoro Ventura de Argumosa y Gándara. En su Erudicción política; Despertador sobre el Comercio, Agricultura y Manufacturas..., aparecida en 1743, dedicará el capítulo V, el más extenso, a analizar el comercio por compañías privilegiadas. Con él pretendía

${ }^{25}$ Ulloa (1740), pp. 70-71.

${ }^{26}$ Las opiniones de Alsedo y Herrera vienen recogidas en un impreso de 1765 con el título de Real Compañia Guipuzcoana de Caracas: Noticias bistoriales prácticas de los sucesos...

${ }^{27}$ Campillo y Cossío (1969), p. 152.

2" Ambas obras fueron recogidas en el Semanario Erudito de Valladares, tomo V, pp. 215-303, y tomo VII, pp. 158-204.

2 Esto es lo que afirman Correa Calderón (1981), p. 197, y Joaquín Maldonado Macanaz (1879), Regalías de los señores..., p. LIX. 
persuadir (a los que no lo están) de lo útil, preciso y conveniente, que son las Compañías, para conseguir un comercio floreciente, y ventajoso a la Nación... ${ }^{30}$.

Solamente dos podrían sacar a España de la situación lamentable en la que se encontraba, «y sin las quales no saldrá de él jamás»: una para Tierra Firme y otra para Nueva España. En ellas recaería todo el comercio con el Nuevo Mundo y se evitaría el contrabando. Y para el comercio interior confía en la creación de compañías para el abasto de telas de lana, seda..., con notables privilegios (reducción de impuestos, derecho de tanteo en la compra de materias primas...).

Argumosa resalta los imponderables beneficios que se seguirían de la formación de estas compañías para restablecer nuestras fábricas. Para él, la libertad de comercio radica en que éste se haga a través de esas sociedades por acciones:

Las Compañías exclusivas son como un padre de familia, que quita a su hijo la libertad de jugar, quando las probabilidades de la pérdida son dobles de las de la ganancia ${ }^{31}$.

Incluso confiará en una compañía para la recaudación de las rentas reales. Su confianza en estas instituciones económicas le llevará a formar parte del equipo, encabezado por José de Carvajal y Lancaster, que, a mediados de la centuria, promoverá la creación de cerca de una decena de sociedades por acciones, a través de la Junta de Comercio y Moneda.

Si Argumosa pretendía con las compañías dar soluciones a nivel nacional, José Zavala y Miranda tenía sus miras puestas en ellas para conseguir establecer un tráfico continuo y ordenado entre los puertos vizcaínos y Buenos Aires. Son varias las obras que de su mano se publicarán en la defensa de esta idea, entre las que hay que mencionar su Manifiesto que al M. N. y M. Leal Señorio de Vizcaya..., de 1743, y su Memorial al Rey Nuestro Señor Don Felipe $V \ldots$, de $1745^{32}$. El ejemplo de la Compañía Guipuzcoana de Caracas debía estar muy presente en sus ideas.

La figura clave para poder comprender la importancia que las compañías de comercio tuvieron dentro de la política económica borbónica es, sin duda alguna, José de Carvajal y Lancaster. Si hasta ahora las opiniones recogidas tuvieron muy escasos resultados prácticos, no ocurrirá lo mismo con las del

so Argumosa y Gándara (1743), p. 185.

31 Idem (1743), p. 300.

${ }^{32}$ Sobre Zavala y Miranda, véase la obra de Mariluz Urquijo. 
secretario de Estado, ya que por su cargo de presidente de la Junta de Comercio y Moneda podrá ver realizadas sus ideas.

En su Testamento político o ideas de un gobierno católico... ${ }^{33}$, escrito en 1745 , antes de su acceso a los cargos señalados anteriormente, apoyará las compañías de comercio como solución al problema del tráfico indiano. Su idea consistía en situar en cada puerto español una compañía que comerciase con Indias a través de los productos de la zona. El mismo lo resume con las siguientes palabras:

Queda dicho que el Comercio de Yndias se debe hacer por Compañias: que éstas se deben situar en distintos Puertos de ambos Mares [se refiere a nuestras costas mediterráneas y atlánticas]; que deben de entrar en ella los Pueblos, que deben nominarse de las Provincias ${ }^{34}$.

En total, cree necesario formar doce compañías. Una en Santander, con el nombre de Castilla la Vieja, para el comercio con Nicaragua, Costa Rica, Panamá... Otra en Galicia, llamada Castilla la Mancha, para el comercio con Campeche, Guatemala, Honduras... La de Andalucía tendría su sede en Sevilla, para el virreinato de Santa Fe. En Asturias se situaría otra para Trinidad y Margarita. Del comercio con la Florida se encargaría una Compañía denominada Galicia. La de Cataluña tendría su sede en Barcelona, y su área exclusiva de comercio sería la Isla Española. La de Vizcaya, en Bilbao, lo haría con Buenos Aires. En algún puerto de Murcia o en Cartagena se situaría otra para Chile. Y, por último, las de Aragón, Valencia, Cádiz y Filipinas comerciarían con Quito, Guayaquil, Puerto Rico y Filipinas, respectivamente. Sin embargo, Tierra Firme y Nueva España seguirían dependiendo de las colonias mercantiles gaditanas, con su sistema tradicional de flotas y galeones.

Su confianza en las compañías de comercio le llevará a afirmar:

Tengo expresado el modo útil de hacer el Comercio de Yndias en doce Compañías que harán opulenta España y temida de los que la desprecian..., ahora quisiera declamar con voces de mi corazón para que se las guarde perpetuamente, que se las trate como a reliquias...; sienta el mayor desagrado el Rey y el mayor rigor qualquiera que se atreva a respirar contra ellas... ${ }^{35}$.

Su vertiginoso ascenso a altos cargos de la Administración del Estado, tras la subida al trono de Fernando VI, y en particular su designación como pre-

${ }^{33}$ Fue publicado en el Semanario de Obras Inéditas (1818).

${ }^{34}$ Carvajal y Lancaster (1745), fol. 127.

3s Idem (1745), fol. $141 \mathrm{v}$. 
sidente de la Junta de Comercio y Moneda, le hará intentar cumplir los objetivos que se había trazado en su Testamento...

José de Carvajal y Lancaster significa el punto culminante de un proceso de apoyo a estas instituciones económicas. Sus ideas denotan la influencia de autores que le precedieron y que mostraron su preocupación por el tema, sobre todo Miguel Alvarez Osorio y Redin, Miguel de Zavala y Auñón y Teodoro Ventura de Argumosa y Gándara. Por su iniciativa y desvelos, en breve tiempo fueron creadas las de Aragón, Extremadura, Sevilla, Granada, Toledo... (de algunas sabemos muy poco, como la de Pozuelo de Alarcón). Será su protector, promotor y principal defensor en la Corte y logrará que obtengan gracias, exenciones y privilegios.

Sin embargo, pronto hubo de afrontar serias divergencias con el secretario de Hacienda, el marqués de la Ensenada, que mantenía ideas bien distintas a las suyas en esta materia. El Real Decreto de 24 de junio de 1752, sancionado por el Rey sin el conocimiento de Carvajal, demuestra la actitud de don Zenón de Somodevilla.

No había transcurrido un mes de la aprobación de ese Decreto, que significaba un durísimo golpe a las compañías creadas, cuando Carvajal eleve al Rey su Representación... sobre el Decreto que abolía las exenciones exclusivas, que gozaban algunas Compañias... ${ }^{36}$.

El Decreto de 24 de junio de 1752 anulaba las gracias de tanteos, derechos exclusivos, exenciones y libertad de cargas reales y concejiles que disfrutaban las fábricas de las compañías y de otros particulares, extendiendo a todas la libertad de alcabalas y cientos̀ en las primeras ventas al por mayor, $y$ de rentas generales para aquellas materias que hubieran de importar del extranjero. Para Carvajal, la aplicación de este Decreto conduciría a la destrucción de las fábricas. Para él, como privilegio exclusivo sólo se podía tener el que gozaban por diez años las de Extremadura, Toledo y Granada para el comercio privativo con Portugal, del que se veían beneficiados todos los fabricantes del reino. El resto de gracias y exenciones, en mayor o menor medida, ya lo disfrutaban otros fabricantes particulares y su derogación sería muy perjudicial, pues siempre la Junta de Comercio y Moneda se mostró partidaria de su concesión a todo aquel que lo solicitara.

En un extenso párrafo de su Representación... analiza la actitud de los contrarios a las compañías de comercio, no olvidándose de subrayar el papel de agentes extranjeros para conseguir su decadencia.

El juicio que le merece el famoso Decreto no puede ser más negativo:

${ }^{36}$ Copia manuscrita en AHN, Sec. Estado, leg. 3208, exp. 330. 
Celebraré engañarme en mi pronóstico, que es funesto, pues entiendo que por el Decreto de 24 de Junio se acabarán las Compañías, las fábricas aumentadas, y algunas de las pocas que había, y sin esperanza de remedio, porque la fé pública se espantó ${ }^{37}$.

Las palabras de Carvajal causaron honda impresión en Fernando VI. El monarca, tras conocer los informes de la Junta de Comercio y Moneda, de algunas compañías y de varios juristas, entre los que estaba Isidoro Gil de Jaz, decidió aprobar el Decreto de 30 de marzo de 1753, que modificaba el anterior de 24 de junio. El derecho de tanteo, la libertad de alcabalas y cientos en las primeras ventas al por mayor y al por menor, la libertad de cargas reales y concejiles..., se extendían a todos los fabricantes del reino, incluidas las compañías.

En su defensa, en los años centrales de la centuria, de las compañías de comercio no se encontró Carvajal solo. Marcelo Dantiny, en sus Diálogos Familiares entre un Irlandés Católico y un Escocés protestante..., aparecidos en 1748, mantuvo ideas muy parecidas. Quería que en España se creasen trece compañías generales por provincias, con un fondo de 40.200 escudos:

las que dispondrían con gran prontitud, y cuidado las reglas de recoger en su mano toda la cosecha, y que no se estragesse, buscarían Maestros de Tegidos, Tintes y Dibujantes, y quando no adelantassen imitarían a los géneros de las Naciones, discurrirían la forma de dar salida a los géneros, asi en lo interior del Reyno como fuera de él, y para las Indias ${ }^{38}$.

El anónimo autor de la Representación hecha al Excmo. Sr. Marqués de la Ensenada sobre la política exterior $e$ interior de España... defiende la utilidad de las compañías al posibilitar la reunión de capitales y facilitar la comercialización de lo producido, aunque reconozca los perjuicios que ocasiona algunas veces el derecho de tanteo ${ }^{39}$.

Isidoro Gil de Jaz, uno de los juristas consultados por Fernando VI tras recibir la Representación... de Carvajal, en su Informe sobre la representación becha al Rey por el Excmo. Sr. Don Joseph de Carbajal y Lancaster... sobre un decreto que abolía las exenciones exclusivas que gozaban algunas Compañías de Comercio y Fábricas... ${ }^{*}$, fechado el 28 de julio de 1752, pedirá al

${ }^{37}$ Carvajal y Lancaster (1789), p. 253. Las ideas de Carvajal fueron recogidas por M. Artola en su artículo «América en el pensamiento español», en Homenaje a $D$. C $i$ riaco P. Bustamante (1969), vol. I, pp. 51-75.

${ }^{38}$ Dantiny (1748), fols. 335 v. y 336.

39 Representación... (1788), tomo XIV, p. 264.

* Su informe lo realizó tras llegar a la Corte para recibir el nombramiento de presidente de la Chancillería de Granada. 
monarca que manifieste su voluntad de proteger a las compañias con todos sus auxilios, mantenga el privilegio exclusivo para el comercio con Portugal por los diez años ya concedidos, habilite medios para que los fabricantes particulares den salida a sus productos, suspenda el derecho de tanteo o lo conceda indistintamente a compañías y particulares, extienda la libertad de alcabalas y cientos en las primeras ventas al por mayor y al por menor a las compañías y a los fabricantes asentados en la Corte, y en los lugares donde estén ubicadas las fábricas de aquéllas, prohíba la extracción de seda...

Su postura final queda resumida perfectamente con las siguientes palabras, en en las que solicita al Rey

que se dignase proteger con el impulso de su poderoso brazo a las compañías, porque estos cuerpos políticos son valuartes, y muros inexpugnables en que funda, y con razón, su mejor defensa la Monarquía. Sin ellas quedará el Comercio tan lánguido como antes estaba, y con ellas puede florecer tanto, que acumulando riquezas, se llegue no solo a la independencia, sino es a poner terror a los enemigos. Si ellas se aumentan abundará el dinero, que es la verdadera sangre del Estado, multiplicará el Real Erario sus ingresos, y conseguirán todos los vasallos la felicidad que V. M. les quiera derramar ${ }^{41}$.

Salvo Uztáriz y Bernardo de Ulloa (y éstos con matizaciones), la opinión mayoritaria de nuestros ilustrados interesados por temas económicos, en la primera mitad del siglo xviII, fue mantener una postura de abierta defensa de las compañías de comercio por acciones, con el disfrute de determinados privilegios, tanto para restablecer nuestra producción interna como para dirigir nuestro comercio con Indias. La puesta en marcha de las creadas por Carvajal y el inicio de las primeras dificultades hizo aumentar progresivamente las críticas hacia estas sociedades.

A finales de 1747 , en un discurso anónimo que lleva por título Quattro Compañias de la Zarza, Zaragoza, Granada y Sevilla ${ }^{42}$, se decía expresamente que las compañías españolas «son la peste y la total destrucción de las Yndias y de la misma España».

Lorenzo Sagárzazu, en sus Reglas y documentos dados por el Sr. Rey Fernando VI para la conservación y aumento de su grandeza, hacía mención a haber expuesto en otro memorial ya al Rey diez razones por las que se mostraba disconforme con la creación de compañias interiores en España. Critica

"Gil de Jaz (1789), p. 275.

42 Quattro... (1748), fol. 129. 
el derecho de tanteo, y sólo abre la posibilidad de que mantengan fábricas de productos que no se trabajen ya en el reino ${ }^{43}$.

Contrario al derecho de tanteo se manifestará al igual Sebastián Antonio Enríquez Sotomira, en sus Discursos politicos y económicos para el bien común de España; además, cree que con estas sociedades sólo se enriquecen unos pocos individuos, resultando perjudicados la inmensa mayoría ${ }^{44}$.

El duque de Sotomayor, en sus Observaciones sobre las Compañías de Comercio (1749), subraya que éstas habían cumplido un buen papel en su tarea de acumular capital ocioso para su empleo en la industria y comercio, pero considera como mucho más beneficioso la extensión de las franquicias a todos los fabricantes sin distinción ${ }^{45}$.

En el Ynforme que embirtud de Real Orden de 14 de Septiembre de 1750 bizo a $S$. M...., Manuel Clemente Rodríguez Requejo refleja la opinión contraria a las compañías como solución al tráfico indiano:

Combiene Señor al mejor servicio de V. M. que con ningún título se permitan formar Compañías para las Provincias de las Yndias, ni sus Yslas, por lo perjudicial que es al grueso del comercio español ${ }^{46}$.

Alejandro Aguado, en su Política española para el más proporcionado remedio de nuestra Monarquía, es de la opinión que «nunca e concedible privativo Comercio a una Compañía, contra la utilidad común de los vassallos» ${ }^{47}$.

Más interesante debió resultar la postura del marqués de la Ensenada sobre estas sociedades por acciones. Pero ni en su Representación becha al Sr. Don Fernando el VI por su Ministro..., ni en su Informe... sobre el estado en que se ballaba el Erario en el año de 1747, ni en sus Puntos de Gobierno ${ }^{48}$ dedica atención al tema.

Incomprensiblemente, Jaime Carrera Pujal destaca como uno de los principales proyectos de Ensenada la creación de compañías de comercio, cuando en realidad este rasgo de la política económica durante el reinado de Fernando VI se debió a la iniciativa de José de Carvajal y Lancaster. Máxime si tenemos en cuenta, como el propio Carrera afirma, que el Decreto de 24 de junio de 1752, por el que desaparecía la situación privilegiada de las compañías, fue sancionado por el monarca a instancias del propio Ensenada.

${ }^{43}$ Sagárzazu (1788), p. 223.

4 Enríquez Sotomira (s. f.), fol. 236.

as Sotomayor (1749). Sobre sus ideas, véase artículo de Rico Linaje.

* Rodríguez Requejo (s. f.), fol. 343 v.

7 Aguado (1750), pp. 215-216.

4 Estas tres obras de Ensenada vienen recogidas en la de A. Rodríguez Villa (1878) bajo el título Don Cenón de Somodevilla..., p. 547. 
Don Zenón de Somodevilla, aunque poseyó acciones en las compañías creadas por Carvajal, no participó en su puesta en marcha ni en sus actividades. Su parecer queda suficientemente reflejado cuando señala:

Las Compañías de Comercio en quanto miren a juntar caudales para promoverle, sería trayción a la Patria no hacer quantas se pudiessen, quanto más mantener las que aya; pero si éstas huviesen de gozar de privilegios, y exempciones, no comunes a todo vassallo, sería lo mismo que declarar que un corto número respectivo al todo, fuesse el que le disfrutasse a su arvitrio en visible perjuicio de los demás, y de las santas intenciones del Rey... ${ }^{49}$.

Tras leer esto no nos ha de extrañar que ante el famoso Decreto mantenga la postura de refrendar su validez, «abriendo un poco la mano» en cuanto a la libertad de cargas reales y concejiles para los maestros y obreros principales de las fábricas.

En los años centrales del siglo xviri, el tema de las compañías de comercio, junto con el de la única contribución, fue uno de los que más interés despertó entre nuestros ilustrados. No nos ha de extrañar que Juan Enrique Graef, en el planteamiento de su obra periódica Discursos Mercuriales Económico-políticos, estableciera entre los temas que daría al público en sus páginas uno que lleva el título de «Pro y contra de las compañías» ${ }^{50}$ (aunque no lo publicó). Y que Fernández de Mesa, en su Tratado legal y político de caminos públicos y posadas, diera una dedicatoria del tenor siguiente:

A los primeros Ministros del Estado miramos cuidadosamente atentos por sí en adelantar las manufacturas y Compañías, huesos en que estriba principalmente el poder y fortaleza de un Reino ${ }^{51}$.

Para Diego Nangle, en su dictamen sobre la petición realizada por algunos comerciantes catalanes para crear la Compañía de Barcelona, de 1754, aunque expresará reparos a algunos de sus 32 artículos, considera muy beneficiosa esta iniciativa al poner en contacto con la metrópoli una zona hasta ahora explotada por los comerciantes extranjeros, en su mayor parte ${ }^{52}$.

$\mathrm{El}$ autor anónimo de los Abusos que se cometen en el manejo y dirección de todas las rentas reales (1759) se referirá a las compañías demostrando su

\footnotetext{
49 Véase AHN, Sec. Estado, leg. 3215, exp. 222, núm. 23.

${ }^{50}$ Graef (1752-56), tomo I, Introducción.

st González Enciso (1980), p. 209, nota 13.

32 Existe otra copia, además de la reseñada en Ya bibliografía, en Miscelánea Ayala, tomo LI, fols. $164-172$.
} 
confianza por las buenas reglas con que fueron creadas y continuaron, pero exigirá un mayor conocimiento de sus actividades ${ }^{53}$.

Por su parte, Nicolás Joaquín de Adame, autor del Nuevo Reglamento para el adelantamiento de las fábricas tanto de seda como de lana, según el editor del Semanario Erudito, obra fechada en 1759 (aunque exista una copia de autor anónimo, de 1774, bajo el título Reglas para establecer en España todo género de Comercio y modo para desterrar a los extranjeros, que coincide íntegramente con la obra de Adame), volverá a insistir en los perjuicios que ocasiona el derecho de tanteo en la compra de materias primas que poseían las compañías, culpándolas, además, de la subida de los precios y de la escasez de la seda ${ }^{54}$.

Bernardo Ward se convertirá, con su obra Proyecto económico en que se proponen varias providencias..., publicada en 1779 pero redactada años antes, en el más firme valedor de las compañías de comercio en la segunda mitad del siglo xvin. Al hablarnos de los medios para hacer navegables nuestros ríos y para crear canales, expondrá la necesidad de crear una compañía holandesa que tuviera estos cometidos, y que debería gozar de la explotación exclusiva de lo por ella canalizado hasta resarcirse de los gastos que hubiera tenido que hacer frente. En esta compañía cifraba todas sus esperanzas:

En las ventajas de España no puede haber duda, ni en que esta providencia será el medio más eficaz para adelantar las fábricas, el comercio, la agricultura y población de estos Reynos ${ }^{55}$.

Entre las misiones que reservaba Ward a su compañía holandesa estaba la de mantener fábricas de cuanto se consumiera en Indias, tomar a su cargo las que hasta entonces dependían directamente del Real Erario, dirigir el comercio triguero en nuestro país tanto de exportación como de importación... Todos nuestros problemas económicos tendrían en la Compañía de Holanda la solución eficaz. El cuadro que nos llegó a pintar no pudo ser más idílico ${ }^{56}$.

Si ya Manuel de Lira o el marqués de Santa Cruz, por citar dos casos conocidos, se habían mostrado partidarios de que súbditos extranjeros tomasen parte en las compañías que proponían, Bernardo Ward destaca por su rotundidad en este sentido. El no duda de la viabilidad de las compañías, pero como conoce los resultados negativos que han tenido la mayoría de las creadas en nuestro país, prácticamente cree que los españoles no están preparados para llevar a buen término estas importantes instituciones económicas. Sirva

s3 Abusos... (1788), p. 65.

34 Adame (1788), pp. 96, 99 y 119.

ss Ward (1779), p. 47.

so Así resulta de la lectura de las pp. 49.50 de su Proyecto. 
de apoyo a este juicio la propuesta hecha por Ward de que las minas de oro y plata de Indias fueran explotadas por una Compañía de Europeos.

No resulta innovador, tampoco, el intentar formar compañías para hacer navegables nuestros ríos, pues cuando escribía su obra ya circulaba por España la obrita, de Carlos de Simón Pontero, Papel instructivo... para los que quieran interesarse en las Compañias de la Navegación de los Ríos Tajo, Guadiela, Manzanares y Xarama... (1756).

Poco a poco, conforme avancemos en la segunda mitad de siglo, vamos a ver cómo las compañías de comercio dejan de figurar entre las soluciones a nuestros problemas económicos. No se cuestionará su utilidad, pero se criticará la situación privilegiada que disfrutan buena parte de ellas. Manuel de Leguinazábal, en su Thesoro de España..., justificará las compañías comerciales no privilegiadas, pero enjuiciará negativamente las creadas por Carvajal ${ }^{57}$.

Francisco Leandro de Viana constituye un eslabón más en la cadena formada por los ilustrados españoles que desde principios del siglo xvin abogaron por la creación de una compañía de comercio que monopolizase el tráfico de España con sus islas Filipinas. Utilizando los argumentos expuestos por Zavala y Auñón, defenderá estas instituciones en su Demonstración del mísero deplorable estado de las Yslas Pbilipinas... ${ }^{58}$ (1765).

En la línea marcada por Bernardo Ward, Vicente Vizcaíno Pérez, en sus Discursos políticos sobre los estragos que causan los censos... ${ }^{59}$ (1766), propondrá formar una compañía que comprase todo el trigo, para evitar las especulaciones de los acaparadores, y se encargase de hacer navegables nuestros ríos.

Francisco Roma y Rosell, en Las señales de la telicidad de España y medios de bacerlas eficaces (1768), no cree que sus paisanos, los catalanes, estén preparados para «la sujeción, unión y confianza que requieren la erección, y subsistencia de estas Sociedades" ${ }^{60}$, por lo que nuevamente hemos de recurrir a lo dicho por Ward en este sentido.

Enrique Ramos, en su Discurso sobre Economía Política, se mostraba contrario a los bancos y compañías particulares por temer sus maniobras acaparadoras.

En la Historia y descripción general de los intereses de comercio de todas las Naciones de Europa..., traducida al castellano por Domingo de Marcoleta y publicada en Madrid entre 1772-74, aunque se desprecia a las compañías de comercio para el tráfico indiano, se ve muy útil su formación para relacionar económicamente España y las islas Filipinas, si bien la ya creada con el título

"Leguinazábal (1764), fols. 43 v, y 44.

se Viana (s. f.), cap. IV, párrafo 13

s9 Carrera Pujal (1943-47), tomo III, pp. 462-466.

soma y Rosell (1768), pp. 272-273. 
de San Fernando de Sevilla podría adecuar su actividad perfectamente a este objetivo ${ }^{61}$.

Juan Antonio de los Heros Fernández, en sus Discursos sobre el Comercio. Las utilidades, beneficios y opulencia que produce... (1775), no dudará de la utilidad de estas sociedades al público y al Real Erario:

Su ruina es superabundantemente compensada por el beneficio que han ocasionado en la emulación de otros fabricantes y circulación de sus fondos ${ }^{62}$.

Aunque centre su análisis en la Compañía de Zaragoza, resultan muy interesantes las causas que para él motivaron el fracaso de las compañias de comercio y fábricas, y los medios que ve necesarios para su restablecimiento. Terminando sus reflexiones con palabras de confianza en este tipo de sociedades, pues no por algo era diputado director de los Cinco Gremios Mayores de Madrid:

Las Reales Compañías (repito) son unos Cuerpos de Comercio importantísimos al Estado, al Rey, y a la Nación... No han expirado sin esperanza de resurrección nuestras Reales Compañías: todavía hay arbitrios para repararlas... ${ }^{63}$.

Por su parte, Pedro Rodríguez de Campomanes mantendrá en sus obras su oposición a estas sociedades mercantiles, como clara consecuencia de su parecer contrario a cualquier estanco o monopolio:

Compañías, monopolios, posturas, tasa, opresión en la justa circulación interior, son incompatibles con la prosperidad común ${ }^{64}$.

Aun así, considera conveniente que las compañías en vigor gocen por un tiempo determinado de una situación privilegiada, hasta conseguir resarcir a sus accionistas del capital invertido, como expresa al referirse a la Compañía de San Fernando de Sevilla o la de la Habana.

Para Campomanes, las causas que influyeron en el fracaso de estas sociedades estriban en su mala gestión administrativa, la pésima calidad de sus tejidos, el abusivo uso de las franquicias otorgadas, su carácter monopolista... De tal forma que si hubiesen permanecido habrian aniquilado todas las fábricas del reino.

${ }^{61}$ Marcoleta (1772-74); en particular, pp, 160, 212 y 275-278 del tomo 1 .

${ }^{62}$ Heros Fernández (1790), tomo XXVII, pp. 22-23.

${ }^{63}$ Idem (1790), tomo XXVII, pp. 37-38.

of Rodríguez de Campomanes (1775-77), tomo I, p. XXIII. 
Opinión bien distinta le merecían los bancos, «únicas compañias que debe y puede favorecer el gobierno».

Nicolás de Arriquivar, en su Recreación política..., publicada en 1779 pero redactada entre 1764-65, mostraba su apoyo a la constitución de una compañía de pesca para todo el reino y de otra para realizar canales de riego.

Francisco Vidal y Cabases, en sus Reflexiones económicas sobre ciertos arbitrios... (1781), retomó la idea marcada por Ward y seguida por Vizcaíno Pérez y por Arriquivar, entre otros, de destacar la importancia que las compañías de comercio podrían tener en la realización de proyectos para hacer navegables nuestros ríos y favorecer, así, la salida de nuestras producciones.

Para Francisco Cabarrús, en su Memoria... para la formación de un Banco Nacional... ${ }^{65}$, las compañías sólo son útiles en un principio, ya que si subsisten estancan las ganancias en un corto número de personas, eliminan la competencia...:

son como los andadores de los niños que sólo sirven hasta que tienen en las piernas la consistencia necesaria para sostenerse, y manejarse por sí mismos.

Defensor, al igual que Campomanes, de la idea de un Banco Nacional, cree que todas las compañías creadas en el reinado de Fernando VI se habían perdido y debían perderse, porque «nunca suplirá en los asuntos meramente mercantiles la indolencia de un Administrador, a la economía, al cuidado, al interés activo de un propietario" ${ }^{66}$. A pesar de este juicio tan severo, al propio Cabarrús se debe la transformación de la Compañía Guipuzcoana de Caracas en la deseada Compañía de Filipinas, que nacerá no exenta de privilegios.

Muy significativo es el ejemplo que representa la obra de Antonio Arteta de Monteseguro Discurso instructivo sobre las ventajas que puede conseguir la industria de Aragón (1783), premiada por la Sociedad Económica de Zaragoza, ya que el autor propondrá para incrementar el comercio exterior aragonés, sobre todo en relación a Indias, la creación de una compañía de comercio con carácter temporal y sin privilegios especiales. Hemos de tener en cuenta que en esa ciudad había existido una compañía de comercio y fábricas, que por esas fechas estaba siendo liquidada ante su fracaso económico.

Gaspar Melchor de Jovellanos no estuvo excesivamente preocupado por la viabilidad de este tipo de sociedades. En palabras de Miguel Artola, su doc-

${ }^{65}$ Esta Memoria... está publicada recientemente en la revista Moneda y Crédito, número 56 (1956), pp. 131-160. Juan Sempere y Guarinos le dedicó un breve comentario en su Ensayo de una Biblioteca..., tomo II, pp. 4-6.

os Véase AHN, Sec. Estado, leg. 2944, exp. 434, p. 6, nota 3. 
trina comercial fue una constante afirmación de su fe en el equilibrio natural que sólo la libertad podría alcanzar. Mantuvo el parecer de que las leyes restrictivas, la tasa de cereales y los monopolios de determinados puertos y compañías eran la causa de la escasez y la carestía.

Frente a este escaso interés por el tema que se denota conforme avanzamos en las obras de literatura económica publicadas en la segunda mitad del siglo xvirI, aún quedan ejemplos como el de Jaime Huguet y Genover, que en su Proyecto sobre el Fomento de nuestra Agricultura, Industria... ${ }^{67}$ pretendía, para conseguir en breves años «el comercio más pujante de la Europa», formar tantas compañías como puertos había en España. Y entre las posibles actividades que podrían llevar a cabo estas sociedades menciona la administración de la renta de tabaco, la de la sal, el abasto de las poblaciones grandes por tres o cinco años, la administración de los pósitos...

Juan Sempere y Guarinos, en su Ensayo de una Biblioteca española de los mejores escritores del reinado de Carlos III, llegará a afirmar que

el pensamiento más útil en mi concepto, y más digno de adoptarse por las demás Sociedades del Reyno [se refiere a las Económicas] es el de establecer una Compañía de comercio, auxiliatoria de los proyectos de la Sociedad... Sin una Compañía de Comercio, a cuyo cargo esté dar salida a los géneros y manufacturas fomentadas por las Sociedades, nunca saldrán éstas de meras tentativas $y$ ensayos ${ }^{68}$.

José Moñino, conde de Floridablanca, fue, en palabras de Viñas Mey, un adepto a las compañías de comercio. Sin lugar a dudas, su intervención debió ser decisiva para que se cumpliera la idea de Cabarrús de crear la Compañía de Filipinas. En su Instrucción reservada... se mostraba bastante optimista de los resultados de esta sociedad:

Si este cuerpo de comercio prospera, como es de esperar, vendrán a ser aquellas islas un manantial de riquezas para la España, y de ellas aumentarán las suyas, su población y sus producciones ${ }^{69}$.

Pero debería limitarse a ser compañía de comercio y no de «dominación y conquistas». Su actividad posibilitaría la disminución de la introducción de géneros extranjeros en España, aunque si resultaba perjudicial al progreso y salida de las manufacturas nacionales, sería preciso detenerla.

67 Sus ideas estaban muy en la línea de lo expresado por Miguel Zavala y Auñón o José de Carvajal y Lancaster, con la particularidad de que las expresó en 1784.

os Sempere y Guarinos (1785-89), tomo V, p. 225.

* Ferrer del Río (1867), p. 233. 
También Valentín de Foronda, en su Miscelánea o Colección de varios discursos..., se mostró favorable a la creación de la Compañía de Filipinas:

... proyecto sublime, que no sólo va a comunicar un nuevo impulso a nuestra navegación, agricultura, industria y comercio, y difundir las riquezas y la felicidad en nuestra Península, sino que tambien será al mismo tiempo una nueva columna que sostenga los edificios medio desmoronados de las Compañías de Caracas y de la Habana ${ }^{70}$.

De ahí que defienda la concesión a ésta del privilegio exclusivo de comercio con esas islas por un tiempo determinado.

León Arroyal, supuesto autor de las Cartas político-económicas escritas por... al Conde de Lerena, partidario a ultranza de la libertad de comercio, apenas prestará atención a las compañías, y la única referencia que se encuentra en su obra es la siguiente cita:

Un reino es comparable a una Compañía de accionistas, sujeta a las estrechas reglas del comercio; que no hay razón para repartir a cada uno menos de lo que se gana, ni más de lo que se pierde, a proporción de las acciones que tenga en la masa común... ${ }^{71}$.

Por su parte, Eugenio Larruga y Boneta, sin duda alguna la persona que mejor conoció la trayectoria de nuestras compañías de comercio, mantiene una actitud dispar. En su manuscrita Historio de la Real y General Junta de Comercio... realizará una defensa de la labor desarrollada por estas instituciones:

... sin embargo de los privilegios de las Compañías han estado tan lexos de contribuir a la decadencia de las fábricas particulares que antes han servido de fomentar su aumento... ${ }^{2}$.

Las compañías no sólo habían dado trabajo a muchos artesanos que antes vivían de limosna, sino que habían favorecido un aumento de los ingresos del Real Erario.

En sus Memorias políticas y económicas... criticará abiertamente la crea-

"Su discurso segundo trata sobre la "Utilidad de la Compañía de Filipinas». Su defensa de estas sociedades está más clara si tenemos en cuenta que era accionista de la Compañía de Filipinas, de la de Caracas y del Banco de San Carlos.

"Aunque hoy ya no se duda de la paternidad de León de Arroyal como autor de las Cartas político-económicas..., en la edición utilizada, debida a Antonio Rodríguez Villa, se atribuye esta obra al conde de Campomanes. La cita aparece en las pp. 247-248.

7 Larruga y Boneta (1789), tomo III, pp. 189-190. 
ción de estas sociedades, su disfrute de privilegios exclusivos, el reducir a meros jornaleros a los artesanos, el enriquecer a unos pocos a costa de muchos, etcétera ${ }^{73}$. Las causas que explicaron su fracaso se hallaban en "la falta de concierto de los que deben protegerlas», la conversión del oficio de protector (clara alusión a Carvajal) en «director despótico de tales establecimientos», el realizar actividades comunes a otros fabricantes españoles con perjuicio de éstos, y «la dificultad que se encuentra en hallar y elegir sujetos idóneos y capaces para desempeñar los oficios de directores» ${ }^{74}$.

El primer traductor de la obra de Adam Smith en España, José Alonso Ortiz, expondrá en sus anotaciones a la Investigación de la naturaleza... sus ideas favorables a la libertad de comercio y a la existencia de compañías de comercio no privilegiadas, alabando la postura seguida en nuestro país de conceder privilegios exclusivos, casi siempre necesarios, con carácter temporal y de no dar a ninguna compañía potestad soberana ${ }^{75}$.

Por último, Ignacio de Asso, en su Historia de la Economía política de Aragón (1798), volverá a tratar el tema de las causas que motivaron el fracaso de estas sociedades mercantiles, a imitación de lo hecho por Heros Fernández o por Larruga, destacando su escasez de fondos para tan amplias actividades, la mala dirección, el excesivo número de asalariados, la admisión de caudales a censo... ${ }^{76}$.

A manera de conclusiones, podemos afirmar que, dentro de la política económica borbónica en el siglo xvirI, la creación de compañías de comercio fue la medida más importante tomada para que el capital privado participase en los deseos estatales de solucionar nuestra deficiente producción industrial y mejorar la comercialización de nuestras producciones.

Nuestros monarcas del siglo ilustrado, a instancias de sus ministros, mantuvieron siempre una actitud favorable a estas instituciones económicas. En su puesta en marcha tuvieron un papel decisivo y fundamental tres figuras claves de la política borbónica: José Patiño, José de Carvajal y Lancaster y José Moñino, conde de Floridablanca.

Prácticamente este tipo de sociedades mercantiles contaron con el apoyo de la mayoría de nuestros compatriotas interesados por temas económicos. Sin embargo, lo que provocará una gran controversia, sobre todo en la segunda mitad de siglo, será el disfrute por las compañías de gracias, exenciones y privilegios no comunes al resto de fabricantes.

Las Sociedades Económicas de Amigos del País, expresión visible de la Ilustración española, no mantendrán una postura uniforme con respecto a este

${ }^{73}$ Idem (1787-1800), tomo VII, p. 360.

74 Idem (1787-1800), tomo VII, pp. 199-203.

73 Smith (1793), tomo III, p. 69.

${ }^{76}$ Asso (1798), p. 138. 
tema, aunque, eso sí, pretendieron que no hubiera diferencias entre las gracias concedidas a fabricantes y compañías. Sirva el ejemplo de la Zaragozana, que premió una Memoria en la que se proponía crear una compañía de comercio para revitalizar la industria y comercio en la región, frente a la Toledana, que para conseguir esos mismos objetivos representó al Consejo de Castilla la extinción de la compañía que existía en la ciudad.

Durante la primera mitad de siglo, la mayoría de nuestros ilustrados defendieron y apoyaron la creación de compañías de comercio privilegiadas. Tan sólo Uztáriz y Bernardo de Ulloa se mostraron disconformes, pero no de una manera rotunda, pues el primero reconoció la posibilidad de formar una Compañía de Filipinas, y Ulloa hizo lo propio con compañías de negociantes interiores.

Hasta 1728, año de la creación de la Compañía Guipuzcoana de Caracas, será una constante entre los preocupados por el tema del comercio indiano la defensa de una Compañía General de Comercio que sustituyese el monopolio ejercido por las colonias mercantiles de Sevilla y Cádiz. A partir de esa fecha se alentará la formación de varias compañías que, a imitación de la de Caracas, hicieran posible que zonas marginadas por ese tráfico, tanto de España como de Indias, comercializaran entre sí sus productos, lo que redundaría en su desarrollo económico y en la disminución del contrabando.

También desde principios de siglo, e incluso antes, se viene defendiendo a estas sociedades mercantiles como la mejor solución para resolver los problemas de nuestra industria y comercio internos.

Es, sin duda alguna, bajo el reinado de Fernando VI cuando las compañías de comercio obtienen su mayor apoyo. Con José de Carvajal y Lancaster y el marqués de la Ensenada se enfrentan, en el nivel más alto de la Administración borbónica, dos valoraciones bien distintas del papel de estas instituciones en nuestra economía.

La actitud crítica hacia estas sociedades mercantiles aumenta notablemente en la segunda mitad de siglo, apoyándose en el fracaso económico de la mayoría de ellas. Buena parte de nuestros ilustrados, en ese período, apenas prestan atención al tema (caso de Jovellanos, León de Arroyal, Alcalá Galiano...) o lo hacen muy de pasada. No cabe duda que confiaban más en la libertad de comercio, tanto interior como exterior, que en las compañías para solucionar nuestros problemas económicos.

Aun así, en los escritos de nuestros «economistas» y políticos subsistirá la postura de defensa de estas sociedades, pues aunque se produzca un aumento progresivo en las críticas a los privilegios que disfrutan por concesión real, resulta claramente demostrativo el parecer de dos figuras de la talla de Campomanes y Cabarrús, opuestos a las compañías, pero que llegan a reconocer 
que éstas puedan gozar, por un tiempo determinado, de una situación privilegiada.

En la segunda mitad del siglo xvirI las compañías serán bien vistas, principalmente como medios para hacer posible la navegación de nuestros ríos y canales y para facilitar nuestro comercio de granos. La preocupación por los temas agrarios, de clara influencia fisiócrata, influyó notablemente en esta actitud. Al igual, y de una manera aún más unánime, se defendió la creación de compañías por acciones en el ramo de los seguros.

Por último, cabe hablar del interés que durante todo el siglo suscitó la necesidad de un mejor aprovechamiento de los recursos de nuestras islas Filipinas, a través de una compañía que tuviera este cometido, con lo que se habría de conseguir disminuir nuestra dependencia del comercio exterior y mejorar nuestra balanza comercial, fiel reflejo de las posturas mercantilistas, entre cuyos autores se encuentran los más acérrimos defensores de las compañías de comercio en nuestro país.

\section{FUENTES IMPRESAS Y MANUSCRITOS DE ILUSTRADOS INTERESADOS POR TEMAS ECONOMICOS (SIGLO XVIII)}

«Abusos que se cometen en el manejo y dirección de todas las rentas reales...» (1788), Sem. Erud., Madrid, tomo XI, pp. 36-80.

AdAmE, N. J. (1788): «Nuevo reglamento para el adelantamiento de las fábricas...», Sem. Erud., Madrid, tomo XI, pp. 81-161.

Aguado, A. (1750): Política española para el más proporcionado remedio de nuestra Monarquia, Madrid, 2:" parte, p. 339.

Alcalá Galino, V. (1793): «Sobre la necesidad y justicia de los tributos», Actas y Memorias de la S. Econ. de Segovia, tomo IV, pp. 269-358.

ARgENTI Y LEYs, F. (1777): Discursos políticos y económicos sobre el estado actual de España, Madrid, Imp. Pedro Marín.

ARgumosa y GÁNdARA, T. V. (1743): Erudicción política; Despertador sobre el Comercio, Agricultura y Manufacturas..., Madrid.

Arriquivar, N. (1779): Recreación política. Reflexiones sobre «El Amigo de los bombres en su tratado de poblacións.... Vitoria.

Arroyal, L. de (1878): Cartas politico-económicas escritas por... al Conde de Lerena, Madrid, ed. de Antonio Rodríguez Villa.

Asso, I. (1798): Historia de la Economia política de Aragón, Zaragoza (existe edición facsímil de 1947).

Cabarrús, F.: Cartas sobre los obstáculos que la naturaleza..., Madrid, ed. de 1973, prologada por J. A. Maravall.

- Expediente titulado «Comercio y establecimiento de los extranjeros en el Reino», en AHN, Sec. Estado, leg. 2944, núm. 434.

Cabrera, J. (1719): Crisis política. Determina..., Madrid.

Campillo, J. del (1969): Lo que bay de más y de menos en España..., Madrid, ed. y estudio de Antonio Elorza, p. 178. 
Carvajal y Lancaster, J. (1753): «Pensamientos del... sobre el Estado político...», Miscelánea Ayala de la Bib. Palacio Real, tomo XXXIX, fols. 148-184.

- (1745): «Testamento político o idea de un Govierno Católico», Miscelánea Ayala, tomo XXXIX, fols. 1-147.

- (1789): «Representación hecha al Rey por... sobre un Decreto que abolía las exenciones exclusivas que gozaban algunas Compañías...», Sem. Erud., Madrid, tomo XXII, pp. $235-254$.

Dantiny, M. (1748): «Diálogos familiares de la Agricultura Indiana entre...», Miscelánea Ayala, tomo LXXI, fols. 190-372. Un ejemplar de esta obra se conserva en la Biblioteca del Instituto Jovellanos de Gijón.

Danvila y Villarrasa, B. J. (1779): Lecciones de Economía Civil..., Madrid, Imp. Joaquín Ibarra.

«Discurso político sobre la necesidad de fomentar los comercios en España», Miscelánea Ayala, tomo XIV, fols. 187-191.

«Discursos anónimos sobre el abatimiento en que se hallaba el comercio de España...», Miscelánea Ayala, tomo L, fols. 8-76.

Enríquez Sotomira, S. A.: «Discursos políticos y económicos para el bien común de España», Miscelánea Ayala, tomo II, fols. 235-244.

Felú DE LA PEÑA, N. (1683): Fenix de Cataluña, compendio de sus antiguas grandezas, Barcelona.

Forond, V. (1787): Miscelánea o Colección de varios discursos..., Madrid, Imp. Benito Cano.

Garanda, M. A. de (1759): Apuntes sobre el bien y el mal de España..., Mss. de la Real Academia de la Historia, p. 320.

GiL DE JAz, I. (1789): «Informe de... sobre la Representación hecha al Rey... por Joseph de Carbajal y Lancaster...., Sem. Erud., Madrid, tomo XXII, pp. 255-279.

Gratf, J. E. de (1752-56): Discursos Mercuriales Económico-políticos, 3 tomos, Madrid, Imp. Agustín de Gordejuela.

Gutiérrez GodínEz, M. (1761): «Proiecto dado a S. Magestad... para un establecimiento de comercio general...., Miscelánea Ayala, tomo I, fols. 414-420.

Heros Fernández, J. A. (1790): «Discursos sobre el Comercio. Las utilidades...», Sem. Erud., Madrid, tomo XXVI, pp. 145-280, y tomo XXVII, pp. 3-223.

Huguet y Genover, J.: Expediente que sobre su proyecto de fomentar nuestra agricultura, industria..., se conserva en AHN, Sec. Estado, leg. 2927, núm. 402.

IRIARTE, B., e IrANDA, marqués de: «Refleciones de... sobre el establecimiento de una compañía de comercio...», Miscelánea Ayala, tomo LIV, fols. 69-83.

Jovellanos, G. M. de (1952-56): Obras publicadas e inéditas de don..., Madrid, BAE.

Larruga $Y$ Boneta, E. (1787-1800): Memorias políticas y económicas sobre los frutos, comercio, fábricas..., Madrid, 45 vols.

- (1789): Historia de la Real y General Junta de Comercio, Mss. en 11 vols. conservado en la Biblioteca del Ministerio de Hacienda.

LegarRa, J. (1719): Comercios de España e Indias. Estado actual de ellos..., Mss. de la RAH, sig. $9 / 4666$.

LeguinazÁbal, M. (1764): «Thesoro de España. Discurso sobre el comercio de España...», Miscelánea Ayala, tomo IV, fols. 1-57.

LIRA, M. de (1821): «Representación dirigida a Carlos II», en Biblioteca Española económico-política, de J. Sempere y Guarinos, tomo IV.

Macanaz, M. de: «Auxilios para bien governar...., Miscelánea Ayala, tomo XV, fols. 214 290, y en Sem. Erud., tomo V, pp. 215-303.

- «Reprèsentación que hice y remití...", Sem. Erud., Madrid, tomo VII, pp. 158-204.

Marcoleta, D. de (trad.) (1772-74): Historia y descripción general de los intereses de Comercio..., 4 tomos, Madrid, Imp. Miguel Escribano.

Matanegur, Abate (1793): Cartas críticas..., Madrid, Imp. Real.

Memoires et considerations sur le commerce et les finances d'Espagne (1761), 2 tomos, Amsterdam. 
Memorias de la Real Sociedad Económica Matritense de Amigos del País (1780-87), 5 tomos, Madrid, Imp. Antonio Sancha.

MoñINo, J. (1867): Obras originales del Conde de Floridablanca, Madrid, ed. de Antonio Ferrer del Río, p. 532.

Muñoz, A. (1769): Discurso sobre Economía política, Madrid, Imp. Joaquín Ibarra.

MuÑoz Y San Clemente, F.: «Reflexiones de... sobre el comercio de las Islas Filipinas...», Miscelánea Ayala, tomo XLII, fols. 78-110.

Nangle, D.: Exposición sobre su parecer a la proposición de los catalanes de crear la Compañía de Barcelona, en AHN, Sec. Estado, leg. 3188, exp. 396.

Naranjo y Romero, G.: Antorcba que alumbra para empezar la restauración..., Mss. de la Real Academia de Ciencias Morales y Políticas.

Nip Ho, F. M. (1769-71): Correo General de España..., 4 tomos.

«Proyecto... que dió un extranjero, proponiendo la formación de una Compañía Universal de nuestras Yndias...», Miscelánea Ayala, tomo VII, fols. 1-79.

Quattro Compañias de La Zarza, Zaragoza, Granada y Sevilla. Año de 1748, Mss. de la Biblioteca Nacional de Madrid, núm. 20261, 5, fols. 120-152.

«Reflexiones sobre las utilidades que podía conseguir la Monarquía española y sus vasayos con el establecimiento de una compañía de comercio...., Miscelánea Ayala, tomo L, fols. $1-7$.

Reglas para establecer en España todo género de comercio..., Mss. de la Biblioteca Nacional, núm. 10946. Se corresponde con la obra ya citada de Adame.

«Representación hecha al Excmo. Sr. Marqués de la Ensenada sobre la política interior y exterior de España...», Sem. Erud., tomo XIV, pp. 218-284, y tomo XV, pp. 3 y ss.

Rodríguez de Campomanes, P. (1775-77): Apéndice a la Educación Popular, 4 tomos, Madrid, Imp. Antonio Sancha.

- (1774): Discurso sobre el Fomento de la Industria Popular, Madrid, Imp. Antonio Sancha.

Rodríguez Requejo, M. C.: «Ynforme... en la negociación del comercio de España con el de América...", Miscelánea Ayala, tomo IV, fols. 341-351.

Rognon, S.: Plan de establecimiento de comercio y manufacturas... en España, en AHN, Sec. Estado, leg. 3188, exp. 356.

Roma y Rosell, F. (1768): Las señales de la felicidad de España y..., Madrid, Imp. Antonio Muñoz del Valle.

SAgárzazU, L. (1788): «Reglas y documentos dados al Sr. Rey Fernando VI para la conservación...», Sem. Erud., Madrid, tomo XIII, pp. 217-232.

SAnTa Cruz de Marcenado, marqués de (1732): Rapsodia Económica política monárquica, Madrid, Imp. Antonio Marín.

SEMPERE y GuARINOS, J. (1801-21): Biblioteca española económico-política, 4 tomos, Madrid, Imp. Antonio Sancha.

- (1785-89): Ensayo de una Biblioteca española de los mejores escritores del reinado de Carlos III, 6 tomos, Madrid. Existe edición facsímil.

Simón Pontero, C. (1756): Papel instructivo... para los que quieran interessarse en la Compañia de la Navegación de los Rios Tajo, Guadiela, Manzanares y Xarama, Madrid, Imp. Antonio Pérez de Soto, p. 49.

SMIT H, A. (1794): Investigación de la naturaleza y causa de la riqueza de las naciones, 4 tomos, Valladolid, Imp. Viuda e Hijos de Santander. Edición moderna en Ed. Bosch, Barcelona, 1983.

Som odevilla, Z. (1788): «Representación hecha al Sr. D. Fernando el VI... proponiendo medios para el adelantamiento de la Monarquía...", Sem. Erud., Madrid, tomo XII, pp. $260-282$.

Sout h UEL, T.: Plan de un comercio nacional, en AHN, Sec. Estado, leg. 3188, exp. 375.

UlloA, B. de (1740): Restablecimiento de las fábricas y comercio español..., Madrid, Imp. Antonio Marín.

UzTÁrIZ, J. de (1724): Theórica y práctica de comercio y de marina..., Madrid. Edición moderna en Ed. Aguilar, Madrid, 1968, p. 454. 
Viana, F. L.: Demonstración del misero deplorable estado de las Yslas Philipinas..., Mss. de la Biblioteca Nacional, núm. 17859. Copia en Miscelánea Ayala.

VIDAL Y CABASES, F. (1781): Reflexiones económicas sobre ciertos arbitrios de propagar la agricultura..., Madrid, Imp. Antonio Sancha.

Vizcaíno PÉrez, V. (1766): Discursos politicos sobre los estragos que causan los censos..., Madrid.

WARD, B. de (1779): Proyecto económico..., Madrid, Imp. Joaquín Ibarra, p. 400.

Zavala y Auñón, M. de (1732): Representación al Rey N. S. D. Phelipe V... dirigida al más seguro aumento del Real Erario, Mss. de la RAH, sig. 9/3792.

\section{BIBLIOGRAFIA}

Por no alargar en excesivo las reseñas bibliográficas, sólo recogeremos las obras y artículos que existen sobre las compañías de comercio en nuestro país en el siglo xviri y sobre la política económica borbónica en general. Para estudios sobre nuestros ilustrados remitimos a la bibliografía aportada por González Enciso y A. Elorza.

Basterra, R. de (1925): Una Empresa del siglo XVIII. Los navios de la Ilustración..., Caracas.

BItAR LETAYFT, M. (1968): Economistas españoles del siglo XVIII. Sus ideas sobre la libertad de comercio con Indias, Madrid, p. 257.

Calla han, W. J. (1972): «La política económica y las manufacturas del Estado en el siglo xviII», Revista de Trabajo, Madrid, núm. 38, pp. 5-17.

Canellas López, A. (1952): "La Real Compañía de Comercio y Fábricas de Zaragoza. Historia de su primer trienion, Chadernos de Historia "Jerónimo Zurita», Madrid, núm. 3, pp. 79-101.

Capella, M., y Matilla Tascón, A. (1957): Los Cinco Gremios Mayores de Madrid, Madrid.

Carrera Pujal, J. (1943-47): Historia de la Economía política, 5 tomos, Barcelona, Ed. Bosch.

Castillo, A. (1971): "Coyuntura y crecimiento de la economía española en el siglo xvirI», Hispania, Madrid, núm. 117, pp. 31-54.

Colmeiro, M. (1965): Historia de la Economía politica en España, Madrid, Ed. Taurus.

Correa Calderón, E. (1981): Registro de arbitristas, economistas y reformadores españoles (1500-1936), Madrid, FUE.

Díaz-Trechuelo Spinola, M. L. (1965): La Real Compañía de Filipinas, Sevilla, p. 366

Elorza, A. (1970): La ideología liberal en la Ilustración española, Madrid, Ed. Tecnos, p. 309.

Enciso Recio, L. M. (1963): Los establecimientos industriales en el siglo XVIII. La mantelería de La Coruña, Madrid, Ed. Rialp, p. 265.

García Ruipérez, M. (1986): La Real Compañia de Comercio y Fábricas de Toledo. Aproximación a la bistoria de su proceso de creación y primeras actividades (1748-1757), Toledo, Caja de Ahorro Provincial.

González ENCISO, A. (1980): Estado e Industria en el siglo XVIII: la Fábrica de Guadalajara, Madrid, FUE, p. 717.

HusseY, R. D. (1934): The Caracas Company 1728-1784, Cambridge, p. 346.

Jiménez Sánc heZ, G. J., y Lasarte Alvarez, F. J. (1963): «La acción en las Compañías privilegiadas (s. XVIII)», Anales de la Universidad Hispalense, Sevilla, año XXIV, núm. II, pp. 1-59. 
LA Force, J. C. (1965): The development of the Spanish textile industry 1750-1800, Berkeley, University of California Press.

Mariluz Urquijo, J. M." (1981): Bilbao y Buenos Aires. Proyectos dieciochescos de compañías de comercio, Buenos Aires.

Martínez Gijón, J. (1968): «Las Sociedades por acciones en el derecho español del siglo xvin», Revista del Instituto de Historia del Derecho Ricardo Levene, Buenos Aires, núm. 19, pp. 64-90.

Matilla QuizÁ, M." J. (1982): «Las compañías privilegiadas en la España del Antiguo Régimen», en La Economia Española al final del Antiguo Régimen, Madrid, tomo IV, Alianza Editorial/Banco de España, pp. 269-401.

Molas Ribalta, P. (1978): «La Junta General de Comercio y Moneda. La Institución y los Hombres*, Cuadernos de Historia, Madrid, núm. 9, pp. 1-38.

MuÑoz PÉrez, J. (1960): «Ideas sobre comercio en el xviII español», Estudios Americanos, Sevilla, núm. 100 , pp. 47-66.

- (1955): «Los proyectos sobre España e Indias en el siglo xvirr: el proyectismo como género», Revista de Estudios Politicos, Madrid, núm. 81, pp. 169-195.

Navarro Miralles, L. J. (1980): «La Compañía de Aragón», Estudios Históricos y Documentos de los Arcbivos de Protocolos, Barcelona, V, pp. 141-160.

Palacio ATARd, V.: El Comercio de Castilla y el puerto de Santander en el siglo XVIII. Notas para su estudio, Madrid, CSIC.

Rico Linage, R. (1978): «La Real Compañía de fábricas y comercio de Granada: su cédula de creación», Actas del I Congreso de Historia de Andalucia. Andalucia Moderna. Siglo XVIII, Córdoba, tomo II, pp. 159-175.

- (1983): Las Reales Compañias de Comercio con América. Los órganos de gobierno, Sevilla, Diputación Provincial-EEHA.

Rodríguez González, M. C. (1982): «La Real Compañía de Comercio y Fábricas de Extremadura", Cuadernos de Investigación Histórica, Madrid, núm. 6, pp. 39-72.

Sureda Carrión, J. L. (1946): "La política económica española del siglo xviII», Anales de Economia, Madrid, pp. 19-46.

Viñas Mey, C. (1922): «Las Compañías de comercio y el resurgimiento industrial de España...», Revista Nacional de Economia, núm. 36, pp. 239-275. 